\title{
Cardiac Device Generator is Being Replaced at Time of Lead Revision
}

National Cancer Institute

\section{Source}

National Cancer Institute. Cardiac Device Generator is Being Replaced at Time of Lead

Revision. NCl Thesaurus. Code C99925.

A cardiac lead requires revision, at which time the generator to the device will be replaced.

(ACC) 